\title{
Em Busca das Práticas: Contribuições Epistemo-metodológicas das Teorias da Prática aos Estudos da Gestão Social
}

\author{
Searching for Practices: Epistemo-methodological Contributions of Practice Theory to Social Management Studies \\ En Busca de las Prácticas: Contribuciones Epistemo-metodológicas de las Teorías de la Práctica a los Estudios de la Gestión Social
}

André Luiz de Paiva

Doutorando em Administração / Universidade Federal de Lavras Professor Substituto na Universidade Federal de Viçosa - Campus de Rio Paranaíba http://lattes.cnpq.br/4280120446698929 https://orcid.org/0000-0002-7895-730X

andrepaiva2@gmail.com

Valderí de Castro Alcântara Doutorando em Administração / Universidade Federal de Lavras Professor Substituto na Universidade Federal de Lavras http://lattes.cnpq.br/2870598651094370 https://orcid.org/0000-0002-6698-0609 valderidecastroalcantara@gmail.com

Elaine Santos Teixeira Cruz Doutoranda em Administração / Universidade Federal de Lavras Professora Substituta da Universidade Federal dos Vales do Jequitinhonha e Mucuri http://lattes.cnpq.br/3672512361395999 https://orcid.org/0000-0003-1070-3052 est_nana@hotmail.com

Luís Fernando Silva Andrade Doutorando em Administração / Universidade Federal de Lavras Doutorando do Departamento de Administração e Economia (DAE). http://lattes.cnpq.br/2468899725153535 http://orcid.org/0000-0001-9963-2048 andradelfs@gmail.com

Resumo: Este trabalho explora como a perspectiva da estratégia como prática contribui para a compreensão das 'práticas de gestão social' e da 'gestão social como prática', em suas relações constitutivas com os praticantes, as práxis e os contextos em que estão inseridas. Buscam-se as contribuições de abordagens teóricas marcadas pela virada prática, especialmente, pela sua recepção no campo das ciências da Administração, a partir dos estudos da estratégia como prática. O foco nas práticas possibilitará ao campo maior ênfase no cotidiano dos processos de organizar, nas práticas organizativas e no entendimento das práticas como fundamentais para a análise social. Nesse sentido, a estratégia como prática contribui a partir da noção de que a gestão social é uma atividade compartilhada pelos sujeitos envolvidos (praticantes), que articula diferentes práticas e práxis, esta última entendida como atividade reflexiva. O artigo realiza uma chamada para os estudos das práticas de gestão social e o entendimento da gestão social como prática.

Palavras-chave: Gestão Social como Prática; Virada Prática; Praticantes; Práxis.

\begin{abstract}
This work explores how the perspective of strategy as practice contributes to the understanding of 'social management practices' and 'social management as practice' in their constitutive relationships with practitioners, praxis and contexts in which they are embedded. We seek the contributions of theoretical approaches marked by the practice turn, especially by its reception in the field of management sciences from the studies of strategy as practice. The focus on practices will enable the field to concentrate more on the daily processes of organizing, on organizational practices and on the understanding of practices as fundamental for social analysis. Thus, strategy as practice contributes starting from the notion that social management is an activity shared by the subjects involved (practitioners) that articulates different practices and praxis, the latter understood as a reflexive activity. This article draws the attention to the studies of social management practices and to the understanding of social management as a practice.
\end{abstract}

Keywords: Social Management as Practice; Practice Turn; Practitioners; Praxis.
Resumen: Este trabajo busca entender cómo la perspectiva de la estrategia como práctica contribuye a la comprensión de las 'prácticas de gestión social' y de la 'gestión social como práctica', en sus relaciones constitutivas con los practicantes, las praxis y los contextos en que están inmersas. Se pretende encontrar las contribuciones de enfoques teóricos marcados por el regreso a la práctica, especialmente, por su recepción en el campo de las ciencias de la Administración, a partir de los estudios de la estrategia como práctica. El enfoque en las prácticas contribuirá al campo mayor énfasis en lo cotidiano de los procesos de organizar, en las prácticas organizativas y en el entendimiento de las prácticas como fundamentales para el análisis social. En este sentido, la estrategia como práctica contribuye a partir de la noción de que la gestión social es una actividad compartida por los sujetos involucrados (practicantes), quienes articulan diferentes prácticas y praxis, esta última entendida como actividad reflexiva. El artículo realiza una llamada para los estudios de las prácticas de gestión social y el entendimiento de la gestión social como práctica.

Palabras clave: Gestión Social como Práctica; Regreso a la Práctica; Practicantes; Praxis.

Texto completo em português: http://www.apgs.ufv.br

Full text in Portuguese: http://www.apgs.ufv.br

\section{Introdução}

Mesmo com os avanços desde o texto seminal "Gestão Social: uma Perspectiva Conceitual" (Tenório, 1998), o campo de saberes e de práticas da gestão social (Araújo, 2012) está aberto e demanda diversas contribuições empíricas e teóricas. Desse modo, pesquisadores desta corrente procuram dialogar com uma miríade de conceitos, que abrangem áreas da Administração, Correspondência/Correspondence: André Luiz de Paiva. Rua Boaventura, 236, Bairro São Francisco, Rio Paranaíba, Minas Gerais, CEP $38810-000$. andrepaiva2@gmail.com
Administração Pública, Serviço Social, Ciência Política e Sociologia, dentre outras (Cançado, 2011; Araújo, 2012; Alcântara, 2015; Garcia, 2016).

Todavia, as diversas contribuições e avanços não eximiram o campo de questões centrais como: O que é gestão social? Quais são as práticas de gestão social? Como se desenvolvem/constroem práticas de gestão social? (França Filho, 2008; Pinho, 2010; 
Cançado, 2011; Alcântara, 2015). Portanto, ainda está aberta a compreensão sobre o que pode ser qualificado ou substantivado como gestão social, em termos teóricos e empíricos. Essa questão se torna relevante já que: "[...] a naturalização desse conceito pode fazer com que a Gestão Social passe a ser associada com tudo o que não for Gestão Estratégica [burocrática; centralizadora; pautada na racionalidade estratégica e instrumental]" (Justen, Moretto Neto \& Garrido, 2014, p. 241) - conforme também destacou França Filho (2008). Segundo Cançado (2011), isso poderia levar a banalização do conceito.

A partir do texto de Tenório (1998), um dos mais influentes do campo, vários outros trabalhos ampliaram o conceito de gestão social, mediante uma diversidade de categorias: democracia deliberativa, dialogicidade, emancipação, esfera pública, interesse bem compreendido, intersubjetividade, racionalidade, solidariedade, sustentabilidade, dentre outras (Cançado, 2011; Cançado, Pereira \& Tenório, 2015). A diversidade de conceitos e categorias fomenta também divergências conceituais e inconsistências, que culminam em críticas (Araújo, 2012; Justen, Moretto Neto \& Garrido, 2014; Pinho \& Santos, 2015a; 2015b). Conforme Araújo (2012, p. 230), "[...] existem (in)consistências nas plurais concepções de gestão social". Para Pinho e Santos (2015b, p. 158) "como todo conceito em processo de constituição, o de GS [gestão social] pode tornar-se um elemento estruturante de um novo campo de saber e de práticas ou ter uma vida efêmera - mais um modismo". Por isso, Justen, Moretto Neto e Garrido (2014, p. 239) afirmam que a gestão social "[...] deve desenvolver a capacidade de autoproblematizar-se, de sentir-se como um problema e de refletir acerca de suas próprias questões não explicitadas".

Uma forma de constatar a diversidade conceitual e problematizá-la reside no âmbito de termos atribuídos, diretamente à gestão social, expressões tais como: gerenciamento (Tenório, 1998), modo de gestão (França Filho, 2003), processo (Tenório, 2005; Cançado, 2011), processo de mediação (Fischer, 2012), ato relacional (Gondim, Fischer \& Melo, 2006), tomada de decisão (Cançado, Tenório \& Pereira, 2011), ação (Cançado, Pereira \& Tenório, 2015), campo de saberes e práticas (Araújo et al., 2014), dentre outras. Diante disso, observa-se, inicialmente, que conceitos diversos são usados para indicar o que a gestão social 'é', 'representa', 'como opera', 'como se define', 'como se pratica', etc. Em muitos casos, apesar da semelhança, correspondem a conceitos com diferentes perspectivas ontológicas e epistemológicas. Percebe-se também uma lacuna que diz respeito à carência de explicitar as práticas de gestão social ou como se pode pensá-la como prática social. Diante disso, neste artigo, pretende-se contribuir a partir das possibilidades de pesquisas, mediante os conceitos de 'práticas' oriundos das teorias da prática (practice theory), especialmente, na sua recepção pelo campo de pesquisa da estratégia na perspectiva da estratégia como prática (SAP).

Cabe esclarecer que não se pretende unificar conceitos de gestão social, tão pouco propor um novo, afinal, entende-se ela:
"[...] como a possibilidade plural de outras gestões, construídas a partir de saberes e de práticas situados" (Justen, Moretto Neto \& Garrido, 2014, p. 248). Além disso, entendendo com Guerra e Teodósio (2015, p. 47) que o campo da gestão social está sendo formado por "múltiplos saberes, definições e práticas" que não se limitam a um conceito único, sendo um "conhecimento construído por múltiplas disciplinas" (Fischer, 2012, p. 11). Portanto, entendese que tal como as práticas (Schatzki, 2001; Reckwitz, 2002; Nicolini, 2013; Santos \& Helal, 2016), o campo de estudos da gestão social é formado por elementos heterogêneos (Justen, Moretto Neto \& Garrido, 2014; Guerra \& Teodósio, 2015).

O pano de fundo desta discussão se refere à 'prática' ser uma categoria central da filosofia, da sociologia e da gestão contemporânea - principalmente, a partir da virada para a prática (practice turn). Esta virada que aconteceu na segunda metade do Século XX é lembrada, sobretudo, pelas contribuições de Pierre Bourdieu (1990), Michel Foucault (1979), Anthony Giddens (2003), Harold Garfinkel (1967), Michel de Certeau (1984), entre outros. Neste sentido, apesar de existirem diferenças conceituais substantivas nas obras destes autores, os mesmos assumem as práticas como elementos fundamentais, por meio dos quais as relações sociomateriais se constituem.

Adiante, além de ser um amplo movimento filosófico e social, a virada prática influenciou, notadamente, os estudos sobre gestão, aprendizagem, organização e estratégia (Zwick, Silva \& Brito, 2014; Feldman \& Orlikowski, 2011; Nicolini, 2013; Santos \& Helal, 2016). Entretanto, apesar da relevância desta abordagem, ela ainda não foi debatida e explorada, detidamente, no campo da gestão social. Cabe notar que este artigo não visa explorar diretamente os teóricos da prática, mas abrir uma agenda de pesquisa, por meio da recepção dos mesmos pelo campo da estratégia como prática e os conceitos relacionados de praticantes, práxis e práticas (Whittington, 2006; Vaara \& Whittington, 2012).

Argumenta-se que a categoria 'prática', entendida em suas dimensões ontológicas, epistemológicas e metodológicas, contribui para pensar as possibilidades da gestão social e de pesquisas nesse campo. Portanto, entende-se que as teorias da prática oferecem contribuições para a construção teórica e caminhos empíricos de pesquisa. Assim, se para Vandenberghe (2014, p. 01) a gestão social é "um campo de práticas em busca de teorias", é possível que uma contribuição teórica possa vir das teorias da prática - neste artigo da perspectiva da estratégia como prática.

Santos e Silveira (2015, p. 80) alertam que se encontram na literatura textos em que "o conceito de prática adotado não é claro", aparecendo noções que incluem, por exemplo, rotinas, eventos, regras, 'mais perto da realidade' e 'mais prático'. Diante disso, é preciso delinear também que o uso do termo 'prática', neste texto, não se refere àquele utilizado pelo campo da gestão social como 'algo real e prático' e nas discussões que se referem ao embate entre teoria e prática (Pinho, 2010; Cançado, Pereira \& Tenório, 2015). E, não se explora aqui a perspectiva das 'comunidades de prática' (Schommer \& França Filho, 2006). Na verdade, estas 
possibilidades citadas podem ser complementadas por conceitos de prática oriundos da virada prática, enquanto uma perspectiva ontológica e epistemológica com contribuições para a consolidação/problematização do campo da gestão social.

Finalmente, objetiva-se neste artigo explorar como a perspectiva da estratégia como prática contribui para a compreensão das 'práticas de gestão social' e da concepção da 'gestão social como prática', em suas relações constitutivas com os praticantes, as práxis e os contextos em que estão inseridas. Buscando, também, realizar uma chamada para os estudos das práticas de gestão social e o entendimento da gestão social como prática.

Além da introdução (1), o texto está estruturado da seguinte forma: (2) teorias da prática, apresentando a perspectiva da SAP (2.1); (3) contribuições das práticas para a gestão social e (4) considerações finais, com uma agenda de pesquisa nessa direção.

\section{Teorias da Prática}

As ciências sociais têm se apoiado amplamente em uma perspectiva prática. Estes esforços têm contribuído para a investigação e descrição de fenômenos, tais como: "a natureza da atividade humana, subjetividade, objetificações, racionalidades, normatividade, linguagem, ciência, poder, bem como a organização, reprodução e transformação da vida social" (Schatzki, 2001, p. 10). Este cenário se justifica, principalmente, pelo movimento da virada para a prática (practice turn), da segunda metade do século XX (Postill, 2010; Fein, 2015). Schatzki (2001) apresenta um panorama geral dos autores e perspectivas da virada prática:

[...] pensadores da prática filosófica, como Ludwig Wittgenstein (1958), Hubert Dreyfus (1991) e Charles Taylor (1985) afirmam que as práticas são ao mesmo tempo subjacentes a sujeitos e a objetos, realçam conhecimentos não-proposicionais e iluminam as condições de inteligibilidade. Por sua linhagem teórica social, a discussão teórica de Pierre Bourdieu (1977, 1990), de Anthony Giddens $(1979,1984)$ e dos etnometodologistas (veja Lynch, 1993) evidencia tais desejos como os de atividade livre do determinismo das estruturas sociais objetivadas e sistemas, para questionar as ações individuais e seu status como fundantes de fenômenos sociais e transcender as oposições rígidas entre estrutura e ação. Para os teóricos culturais como Michel Foucault (por exemplo, 1976, 1980) e Jean-François Lyotard $(1984,1988)$, entre outros, falar de práticas é descrever a linguagem como atividade discursiva em oposição ao discurso estruturalista, semiótico, e concepções pósestruturalistas dele como estrutura, sistema ou discurso abstrato. $\mathrm{E}$ entre, por fim, os efeitos que animam o estudo teórico da prática da ciência e da tecnologia (por exemplo, Rouse 1996b; Pickering 1995a) são o desenvolvimento de conceitos de ciência como atividade em oposição à representação e à reconsideração das dicotomias humanistas entre entidades humanas e não humanas. (Schatzki, 2001, p. 10).

Nesta direção, Schatzki (2001) classifica as influências teóricas do campo de estudos das práticas em quatro eixos: filósofos (Wittgenstein, Dreyfus e Taylor), teóricos sociais (Bourdieu, Giddens), teóricos da cultura (Foucault, Lyotard) e teóricos de ciência e tecnologia (Latour, Rouse, Pickering). O Quadro 1 apresenta alguns conceitos de prática dos principais representantes da virada (Nicolini \& Monteiro, 2017). No quadro, são visíveis as diferentes concepções de práticas, variando em níveis de amplitude (micro e macro) e dinâmica (mais estáveis e mais dinâmicas).

Quadro 1: Definição da prática.

\begin{tabular}{|c|l|}
\hline Autor & \multicolumn{1}{|c|}{ Definição da prática } \\
\hline Pierre & $\begin{array}{l}\text { "Practice = (Habitus X Capital) + Field" (Bourdieu, 1984, } \\
\text { p. 101). }\end{array}$ \\
\hline Michel de & $\begin{array}{l}\text { "The microbe-like operations proliferating within } \\
\text { technocratic structure and deflecting their functioning by } \\
\text { means of a multitude of 'tactics' articulated in the details of } \\
\text { everyday life" (De Certeau, 1998, p. xi). }\end{array}$ \\
\hline Harold & $\begin{array}{l}\text { "Contingent ongoing accomplishments" (Garfinkel, 1967, } \\
\text { p. 11). }\end{array}$ \\
\hline Anthinkel & $\begin{array}{l}\text { "Regularized types of acts" (Giddens, 1984, p. 75) "The } \\
\text { basic domain of study of the social sciences, according to } \\
\text { Giddens } \\
\text { the theory of structuration, is neither the experience of the } \\
\text { individual actor, nor the existence of any form of social } \\
\text { totality but social practices ordered across space and time" } \\
\text { (p. 1989). }\end{array}$ \\
\hline "Any coherent and complex form of socially established \\
cooperative human activity through which goods internal to \\
that form of activity are realised in the course of trying to \\
achieve those standards of excellence which are \\
appropriate to, and partially definitive of, that form of \\
activity, with the result that human powers to achieve \\
excellence and human conceptions of the ends and goods \\
involved, are systematically extended" (Maclntyre, 1981, p. \\
175).
\end{tabular}

Fonte: Adaptado de Nicolini e Monteiro (2017, p. 4).

Postill (2010) distingue duas gerações/movimentos de teóricos da prática: a primeira, constituída por expoentes, que construíram as bases do que é conhecido hoje como teoria da prática (Bourdieu, Foucault, De Certeau, Garfinkel, Giddens, entre outros) e; a segunda, composta por pesquisadores, que se engajam no estudo das contribuições do primeiro movimento, testando e construindo novas bases teóricas para o referido corpo de conhecimento (Schatzki, Reckwitz, Warde, Knorr-Cetina, Savigny, e outros).

De modo geral, os autores que constituem a primeira geração da virada para a prática procuravam libertar a agência, ou seja, liberarem a capacidade dos indivíduos agirem e mudarem o mundo das amarras dos modelos estruturalistas e sistêmicos, evitando, ao mesmo tempo, as armadilhas do individualismo metodológico (Foucault, 1979; Giddens, 2003; Bourdieu, 1990; Postill, 2010). Para tanto, reconheciam as práticas como meios de interação entre os atores, em suas atividades corporificadas e os contextos estruturantes (Postill, 2010).

Como exemplo, para Bourdieu (1990), os pressupostos estruturais do mundo são internalizados pelos sujeitos em seus habitus e objetivados em práticas, que constituem campos sociais. A partir das disposições do habitus, todavia, estes atores são capazes de agir (Bourdieu, 1990). Foucault (1979) apresenta o conceito de disciplina, formado pelos constrangimentos estruturais e pelo poder impressos nos corpos dos sujeitos. Conforme a disciplina, as pessoas aprendem a construir e autorregular suas práticas corporais. Procurando modificar a discussão em torno da dicotomia entre estrutura e agência, Anthony Giddens (2003) apresenta a noção de dualidade da estrutura na sua teoria da estruturação. Nesta perspectiva, discorre que a ordem social é tanto produzida quanto reproduzida, na prática dos sujeitos, ou seja, afirma que não existe uma supremacia da estrutura determinante das ações individuais, nem o contrário. De forma geral, nessas perspectivas, a capacidade de agência dos atores é mediada pelas práticas (Whittington, 2006; Albino \& Gonçalves, 2008). 
Esses precursores da teoria da prática, na visão de Whittington (2006), apresentam três temas principais em sua pauta de pesquisa: (a) a compreensão de como os campos sociais (Bourdieu), sistemas (Giddens) ou instituições disciplinares (Foucault) definem as práticas, que, ao mesmo tempo, restringem e possibilitam a atividade humana; (b) a explicitação do "como" é feito e não apenas do "o que" é feito, colocando-se, como desafio, capturar o "senso prático" (Bourdieu) ou as idiossincrasias da vida cotidiana (De Certeau), por exemplo; (c) explicar como os agentes tomam posição no campo em que jogam (Bourdieu), negociam cotidianamente com as estruturas do seu espaço de ação (De Certeau) ou descobrem "ontological gaps" para exercer poder e promover mudanças (Giddens). (Albino \& Gonçalves, 2008, p. 3).

No que se refere aos pesquisadores, que compõem a segunda geração de estudos da prática, destaca-se o interesse em definir conceitos gerais de prática (Warde, 2005). Além disso, a segunda geração aproxima estes estudos de áreas como a teoria organizacional, estudos de consumo e outros campos das ciências sociais aplicadas (Postill, 2010; Fein, 2015). De toda forma, "[...] ambas as gerações foram essenciais para o desenvolvimento dos estudos sobre a prática no campo organizacional" (Zwick, Silva \& Brito, 2014, p. 386).

Verzelloni (2016) coloca que a redescoberta da prática é um importante movimento, que contribuiu para o desenvolvimento dos estudos organizacionais e de gestão. Na mesma direção, para Corradi, Gherardi e Verzelloni (2010), nos últimos 20 anos, a perspectiva das práticas ganhou espaço nos estudos sobre organização, aprendizagem e conhecimento. Contudo, a prática permanece como um uma palavra polissêmica (Verzelloni 2016) ou como um conceito guarda-chuva (Gherardi, 2006; Verzelloni 2016). Verzelloni (2016) apresenta algumas das diferentes formas, que as pesquisas na direção delas podem ser referidas: ponto de vista baseado na prática; lente prática; conhecimento na prática; perspectiva prática; abordagens baseadas na prática e estratégia como prática.

Para Reckwitz (2002), o rótulo prática e prática social remete a diversos autores com afinidades e diferenças. Schatzki (2001) também afirma que não existe uma teoria unificada da prática. Há um consenso entre pesquisadores de que as práticas se referem a um arranjo de atividades corporificadas, conectadas por objetos naturais, híbridos e/ou artefatos, compartilhadas por meio de um entendimento prático e perpetuadas por uma performance contínua (Schatzki, 2001; Reckwitz, 2002; Soares \& Bispo, 2017). Assim, apesar das diferentes percepções, existem elementos e noções em comum (Soares \& Bispo, 2017).

Santos e Helal (2016, p. 11), a partir de Nicolini (2013), apresentam alguns elementos que se constituem as práticas: as práticas são compostas por atividades; se organizam em torno de um fim; não existem isoladamente; são coletivas; "sempre [existem] inconsistências parciais e tensões dentro dos componentes de uma prática e entre diferentes práticas"; "são historicamente situadas"; "a natureza social e material das práticas também as torna inerentemente situadas em um momento particular no tempo, espaço e história"; "as práticas e seus agenciamentos capacitam certos cursos de ação em detrimento de outros" (Santos \& Helal, 2016, p. 11), dentre outras. Segundo Schatzki (2001), as diferenças no campo consistem, contudo, na natureza e no sentido desse conjunto de atividades, bem como na relação entre atores, objetos e demais componentes das práticas. Schatzki (2005) apresenta que a vida social é formada por um nexo de práticas humanas e arranjos materiais.

By practices, I mean organized human activities. Examples are political practices, cooking practices, educational practices, management practices, shop floor practices, and design practices. Any practice is an organized, open-ended spatial-temporal manifold of actions. The set of actions that composes a practice is organized by three phenomena: understandings of how to do things, rules, and teleoaffective structure. (Schatzki, 2005, p. 471).

O autor apresenta também o que ele entende pelo "lugar do social", que é "a mesh of practices and material arrangements" (Schatzki, 2005, p. 472). Portanto, o "[...] social é um campo de práticas constituídas, materialmente entrelaçadas, centralmente organizadas em torno de entendimentos práticos compartilhados" (Schatzki, 2001, p. 13). No escopo desta perspectiva, o denominado campo de práticas se refere a um denso emaranhado de práticas humanas, que abrangem toda a realidade social (Schatzki, 2001; Postill, 2010). Neste campo, é possível investigar fenômenos, tais como: significado, ciência, poder, linguagem, instituições e transformações históricas (Schatzki, 2001; Santos \& Silveira, 2015).

Outra contribuição relevante para o entendimento das práticas é a de Reckwitz (2002). O autor descreve as principais características das teorias da prática, a partir de Bourdieu, Giddens, Taylor, Foucault, Garfinkel, Latour, Schatzki e outros, mostrando essa perpectiva como uma alternativa para as visões culturalistas mentalistas, textualistas e intersubjetivistas. Reckwitz (2002) argumenta que as teorias da prática oferecem contribuições importantes para temas da teoria social, a partir do momento, em que o social não é colocado no mental, no discurso, nem na interação, mas se trata das práticas (como unidade de análise social). Nas palavras de Reckwitz (2002, p. 249-250):

A 'practice' (Praktik) is a routinized type of behaviour which consists of several elements, interconnected to one other: forms of bodily activities, forms of mental activities, 'things' and their use, a background knowledge in the form of understanding, know-how, states of emotion and motivational knowledge. A practice - a way of cooking, of consuming, of working, of investigating, of taking care of oneself or of others, etc. - forms so to speak a 'block' whose existence necessarily depends on the existence and specific interconnectedness of these elements, and which cannot be reduced to any one of these single elements. Likewise, a practice represents a pattern which can be filled out by a multitude of single and often unique actions reproducing the practice (a certain way of consuming goods can be filled out by plenty of actual acts of consumption).

Finalmente, Reckwitz (2002) explora a relevância de diversos elementos como: corpo (práticas são atividades corporais rotineiras), mente (as práticas são conjuntos de atividades mentais também), coisas (os objetos são componentes das práticas), conhecimento (uma prática social específica contém formas específicas de conhecimento), discurso/linguagem (as práticas discursivas são um tipo de práticas entre outras), estrutura/processo (as práticas sociais são rotinas de mover o corpo, de entender, de usar coisas, etc.) e agente/indivíduo (os agentes carregam e realizam práticas).

Em decorrência dessas características (Reckwitz, 2002; Schatzki, 2001; 2005; Santos \& Silveira, 2015; Soares \& Bispo, 2017), para Warde (2005), as teorias da prática não são nem 
individualistas, nem holísticas. Elas apresentam uma leitura plural e flexível da vida social, contemplando um conjunto de fenômenos que se manifestam em atividades enraizadas em contextos. Em outras palavras, segundo Postill (2010), os estudos baseados em práticas procuram superar os excessos do individualismo e do holismo metodológico. Isto oferece meios para superar dicotomias clássicas, tais como: agência versus estrutura, subjetividade versus objetividade e social versus material. Santos e Silveira (2015, p. 82) colocam que, nessa perspectiva, se pode focar nas dinâmicas das práticas como ponto inicial das análises.

Em suma, conforme afirmam Golsorkhi, Rouleau, Seidl e Vaara (2010), a virada para a prática nos estudos sociais permitiu que os mesmos estudassem os aspectos das relações sociais e sua construção, em um contexto real, a partir de uma investigação em profundidade. Além disso, rompe com o individualismo metodológico ao enfatizar que a atividade precisa ser entendida como possibilitada ou limitada por práticas sociais e aspectos materiais da realidade. Santos e Silveira (2015) colocam que os estudos organizacionais se distanciaram do que as pessoas fazem cotidianamente, optando por um conceito abstrato de organização, pois os estudos se preocupam demais com os elementos formais e estáticos das organizações e, menos com o feito no cotidiano, no emergente e nas dinâmicas. Para os autores, os estudos das práticas contribuem para o direcionamento do foco novamente para a "realidade vivida pelas pessoas nas organizações" (Santos \& Silveira, 2015, p. 79).

Por fim, as contribuições de diferentes pensadores auxiliaram a entender as práticas organizacionais, a partir de orientações ontológicas e epistemológicas distintas, conforme já expresso. Em destaque, a virada prática influenciou, significativamente, a forma de pensar a estratégia nas organizações se consolidando no campo da estratégia como prática (Whittington, 2006; Vaara \& Whittington, 2012).

\subsection{Estratégia como Prática (Strategy as Practice)}

A perspectiva da estratégia como prática (strategy as practice, SAP), assim denominada por Whittington (1996), se caracteriza como uma corrente de estudos, que busca entender o fenômeno da estratégia, por meio da investigação e consideração das práticas sociais e das interações interpessoais nas organizações. Esta abordagem recebeu influência direta dos teóricos da prática, sobretudo daqueles pertencentes ao primeiro movimento:

The strategy discipline's growing engagement with activity fits with a wider 'practice turn' in contemporary social theory, gathering momentum since the 1980s (Schatzki et al. 2001; Reckwitz 2002). Seminal theorists of this practice turn include Pierre Bourdieu, Michel de Certeau, Michel Foucault and Anthony Giddens (Whittington, 2006, p. 614).

Nessa direção, pós-virada prática, Jarzabkowski, Balogun e Seidl (2007) entendem como estratégia as atividades que a organização, constituída por diversos atores internos e externos, desenvolve em seu cotidiano, por meio de práticas, para alcançar fins e objetivos (podendo ser fins econômicos, públicos, sociais, etc.). Jarzabkowski e Spee (2009) se referem à pesquisa em estratégia como prática como aquela preocupada com o "trabalho estratégico" (strategizing): a atividade que constrói a estratégia nas organizações. Nas palavras de Vaara e Whittington (2012, p. 286), "o insight chave desses estudos tem sido que o trabalho estratégico (strategizing) depende das práticas organizacionais e também outras práticas que afetam significativamente o processo e o resultado das estratégias".

Whittington (2006) entende a estratégia como um fenômeno constituído por três categorias inter-relacionadas: práticas, práxis e praticantes. Assim, as práticas, segundo Jarzabkowski e Spee (2009), podem ser entendidas como um feixe complexo de ações envolvendo aspectos sociais, materiais e formas corporificadas 'do fazer', que são inter-relacionados, porém nem sempre articulados ou remetendo à consciência do ator envolvido. Segundo Whittington (2006), práticas são padrões de comportamento situados no espaço e no tempo, que influenciam o pensamento e a ação humana, podendo envolver saberes, culturas, valores, crenças, artefatos, discursos, etc. Nesse sentido, Whittington (2006) segue as colocações de Schatzki (2001) e Reckwitz (2002) acerca do conceito de práticas. Por sua vez, a categoria práxis, de acordo com Whittington (2006), se apoia em Reckwitz (2002), e se refere à 'atividade de fato', a uma forma de ação reflexiva, realizada pelos atores organizacionais. Brito, Brito, Borges e Andrade (2014) acrescentam a noção de que a práxis é uma atividade autônoma e criativa: "Praxis is an artful and improvisatory performance" (Whittington, 2006, p. 620). Conforme Jarzabkowski, Balogun e Seidl (2007), a práxis diz respeito às atividades desenvolvidas no cotidiano organizacional e que exerce alguma implicação direta na construção das estratégias, podendo ser observada em reuniões, apresentações, textos institucionais, consultorias, conversas no cotidiano, etc. Finalmente, os praticantes envolvem os atores que, de alguma forma, participam do trabalho estratégico, tanto membros internos da organização quanto externos e em diferentes níveis (Whittington, 2006; Brito et al., 2014).

Conforme Whittington (2006), estas categorias são articuladas de modo a prover um vocabulário consistente para o estudo de temas que, embora centrais nas teorias das práticas, são recorrentemente expressados de diferentes modos. Com isso, Jarzabkowski, Balogun e Seidl (2007) concebem que é na relação entre os três conceitos que acontece o strategizing, ou seja, o conjunto de atividades que constrói os resultados das estratégias realizadas pelos atores. O strategizing se relaciona com a forma com que os estrategistas fazem as estratégias, em seu contexto e em interações diversas (Jarzabkowski, Balogun \& Seidl, 2007; Walter \& Augusto, 2012). Portanto, "[...] o strategizing inclui as ações, as interações e as negociações de atores múltiplos, bem como as práticas situadas que esses atores utilizam para realizar uma atividade também situada e socialmente realizada" (Walter \& Augusto, 2012, p. 134).

Recentemente, Silva e Gonçalves (2016) mapearam os princípios convergentes das diversas teorias da prática, tendo em vista a construção de uma agenda de pesquisas para a SAP. Os autores entendem que desdobramentos da teoria da prática podem impactar na pesquisa em estratégia como prática em diferentes aspectos. Primeiramente, é possível compreender as organizações a partir da investigação da experiência vivida pelos praticantes, nos 
agrupamentos de práticas, que constituem seu cotidiano. Nessa direção, a estratégia emerge da dinâmica de práticas culturais constituídas pela linguagem, objetos, corpos, entre outros elementos. Adiante, os autores consideram que a prática pode ser entendida em uma dimensão ontológica relacional, especialmente, a partir de Schatzki. Estas concepções implicam em certos compromissos metodológicos. É necessário que o pesquisador reconheça a natureza subjetiva e intersubjetiva do conhecimento científico e adote métodos e perspectivas, que estejam alinhadas a esta noção. Silva e Gonçalves (2016) sugerem o uso da etnografia multi-situada e da cartografia para a investigação da produção de sentidos pelos atores sociais nos campos.

Nesta direção, esta perspectiva pode contribuir para o entendimento das práticas de gestão social e da concepção da gestão social como prática - abrindo uma ampla agenda de pesquisas nessa direção.

\section{Contribuições das Práticas para a Gestão Social}

\subsection{Gestão Social}

Existem diversos debates no campo da gestão social. Araújo (2012, p. 225) defende a concepção da gestão social como campo interdisciplinar e em construção - "[...] se trata de um campo de conhecimentos em construção em estágio ainda preliminar no qual prevalece o caráter multidisciplinar, tendendo a interdisciplinaridade" - enquanto Cançado (2011) argumenta que a gestão social já alcançou muito progresso e possui um corpo teórico consistente, se aproximando do seu primeiro paradigma (Cançado, Pereira \& Tenório, 2015).

Com os avanços, o campo vem dialogando com uma miríade de conceitos (Cançado, 2011; Araújo, 2012; Alcântara, 2015), como: esfera pública, esfera social, território, cidadania, economia solidária, tecnologia social, movimentos sociais, avaliação, democracia deliberativa, participação social e outros já citados neste artigo. Como já afirmado, apesar de seu desenvolvimento, uma parte significativa das críticas à gestão social se refere à dificuldade de 'materialização' do conceito, na sociedade brasileira, suas inconsistências e a carência de um entendimento ou forma de qualificar 'o que é' e 'o que não é' gestão social (Pinho, 2010; Araújo, 2012; Justen, Moretto Neto \& Garrido, 2014; Pinho \& Santos, 2015a; 2015b). Uma breve análise da chamada de trabalhos para o IX Enapegs (UFRGS, 2016), evento principal da Rede de Pesquisadores em Gestão Social, revela uma pluralidade de temas, adjetivos e conceitos. lizuka e Junqueira (2013) revelaram, também, ao analisar os anais do Enapegs, que existe uma diversidade de temas. Na visão de Pinho e Santos (2015a), isso indica imprecisão conceitual.

O fato é que, nos tempos atuais, a noção de GS [gestão social] trafega em distintos campos gramaticais, semânticos, teóricos e epistemológicos enveredando, muitas vezes, pela indeterminação, trafegando entre as condições de substantivo, adjetivo, de sujeito e de suporte, reportando-se a múltiplas possibilidades de prática e de concretização. Seus formuladores qualificam a GS como "processo", "produto" ou "subproduto", relacionando-a a formas bastante diferenciadas de produção de saberes, de realidade, e mesmo a métodos particulares de gestão da res publica (Pinho \& Santos, 2015b, p. 4).

Buscando entender esta colocação no sentido da problematização proposta por Justen, Moretto Neto e Garrido (2014) e de avanços conceituais de Cançado, Pereira e Tenório (2015), visitam-se diversos conceitos/definições/noções de gestão social propostas por diferentes autores, buscando entender o 'operador conceitual' que ora substantiva, adjetiva ou qualifica a gestão social, indicando 'o que ela é' e/ou 'almeja ser'. Dessa forma, nos conceitos, percebe-se que a gestão social é 'operacionalizada', conceitualmente, de diferentes formas, como: gerenciamento (Tenório, 1998), modo de gestão (França Filho, 2003), processo (Tenório, 2005; Cançado, 2011), processo de mediação (Fischer, 2012), ato relacional (Gondim, Fischer \& Melo, 2006), tomada de decisão (Cançado, Tenório \& Pereira, 2011), ação (Cançado, Pereira \& Tenório, 2015; Alcântara, 2015); campo de práticas (Araújo, 2014), dentre outras. Emerge também a questão que as operacionalizações não indicam quais são as 'práticas da gestão social' ou como a gestão social pode ser concebida, em termo de suas 'práticas' ou como 'prática social'. Por isso, argumenta-se que as teorias da prática podem auxiliar na apresentação da discussão do que são 'práticas de gestão social' e como são possíveis contribuições epistemo-metodológicas ao adotar a 'gestão social como prática'.

Trabalhos de autores, que caminharam nessa direção, foram Peres Júnior (2013), Peres Júnior, Pereira e Oliveira (2013) e Silva e Pimentel (2014). Peres Júnior (2013) e Peres Júnior, Pereira e Oliveira (2013) a partir da teoria da estruturação de Giddens e da literatura em sistemas deliberativos estudaram práticas de gestão social. Os autores definem a gestão social como "conjunto de práticas de ação gerencial dialógica" (Peres Júnior, Pereira \& Oliveira, 2013, p. 21), ou ainda "um conjunto de práticas de ações gerenciais dialógicas voltadas para o interesse público" (Peres Júnior, Pereira \& Oliveira, 2013, p. 24). Por sua vez, Silva e Pimentel (2014, p. 1) discutem "as contribuições de uma abordagem da estratégia como prática social para lidar com o processo de autoorganização na gestão social”. Para Silva e Pimentel (2014, p. 2), a abordagem de estratégia como prática social "oferece potencial para a compreensão de como se dá a referida auto-organização dos grupos sociais marginalizados, bem como para promovê-la por meio da gestão social".

No entanto, nenhum dos textos explora as contribuições epistemológicas e metodológicas das teorias da prática para a gestão social, de forma ampla (por meio das categorias práticas, praticantes e práxis), e não propõe o tratamento da 'gestão social como prática'. Portanto, mesmo com estes estudos, nenhuma pesquisa apresentou, de forma ampla, o direcionamento de pesquisa/chamada para os estudos das práticas de gestão social e o entendimento da gestão social como prática. 


\subsection{Contribuições para a Compreensão das 'Práticas de Gestão} Social' e da 'Gestão Social como Prática'

Nessa parte, apresentam-se as contribuições das práticas, especialmente, categorias empregadas na estratégia como prática (SAP), para a compreensão das 'práticas de gestão social' e da 'gestão social como prática' em suas relações constitutivas com os praticantes, as práxis e os contextos em que estão inseridas.

(1) As abordagens da prática permitem avançar na discussão sobre o 'objeto de análise' da gestão social, enquanto campo plural/heterogêneo e abre possibilidade de considerar como objeto (em sentido epistemológico) não apenas a 'organização' (reificada), mas o ‘organizar práticas'.

Ao posicionar as práticas como a unidade básica de análise da realidade social, Reckwitz (2002), bem como outros teóricos da prática, procuram dar ênfase também na agência humana, que se desenvolve, por meio de um conjunto de comportamentos permeados por aspectos estruturais e institucionais, inseridos em um contexto próprio. Neste ínterim, as teorias da prática possuem como pressuposto que: "[...] o ator humano não é nunca um indivíduo discreto separado do contexto, mas sim um ser social cujas possibilidades são definidas pelas práticas em que ele ou ela está imerso" (Vaara \& Whittington, 2012, p. 288).

Assumindo as práticas para o estudo das organizações (no âmbito da gestão social) e seus fenômenos relacionados, deve-se considerar as práticas de organizar (práticas organizativas) desenvolvidas no cotidiano organizacional como unidade de análise. Assim, é necessário destacar as ações e as interações humanas organizadas, representadas por diferentes praticantes e situadas em um contexto socio-histórico, uma vez que, conforme Jarzabkowski, Balogun e Seidl (2007 p. 6) '[...] atores não estão agindo isoladamente". Pode-se buscar em Theodore Schatzki (2001; 2005) elementos para compreender a realidade das pessoas nas organizações (Santos \& Silveira, 2015) e como se constroem práticas de gestão social.

Nesse sentido, é necessário o desenvolvimento de estudos voltados para as práticas organizacionais e práticas organizativas, que se aproximam mais do conhecimento de 'como as coisas acontecem' nas organizações (Santos \& Silveira, 2015) e nos processos de organizar (Peci, 2014). Santos e Silveira (2015, p. 82) mostram que, para Schatzki, ao se estudar as organizações se deve: "delimitar as atividades humanas (e/ou os eventos, episódios, interações) que compõem o fenômeno de interesse", "identificar a malha prática-arranjo da qual essas atividades (eventos, episódios, interações) fazem parte", "determinar possíveis outras malhas prática-arranjo com as quais essa malha específica possa estar conectada" e "traçar as cadeias de ação dos agentes humanos e não-humanos que circulam dentro dessa malha específica, que passam por meio dela e/ou que a conectam com outras malhas e que ajudam a reforçar as suas características atuais (ou a transformar) o fenômeno de interesse".

Peci (2014) defende a importância de considerar como objeto de análise não apenas a organização (reificada), mas o 'organizar'.
Segundo a autora, isso representa um avanço, tendo em mente que "a Administração como campo de conhecimento foi historicamente relacionada com um objeto aparentemente sólido de análise: as organizações, preferencialmente, a grande organização burocrática" (Peci, 2014, p. 729) - visão orientada pela hegemonia da matriz funcionalista. Por isso, "Desnaturalizar as organizações é importante para entendermos o que é o nosso objeto de estudo e não o encarar como algo estático" (Santos \& Silveira, 2015, p. 92).

O foco no 'organizar' de Peci (2014) é acompanhado por trabalhos, que discutem os processos de construção das práticas organizacionais: "[a] crise do discurso administrativo centrado na organização abre espaço para novas concepções do nosso objeto de estudo, de natureza mais processual, focalizando o processo de organizar ou as práticas organizacionais" (Peci, 2014, p. 730). Nesse sentido, organizar significa, para Clegg, Kornberger e Rhodes (2005), um processo de tensão, plural, com uma diversidade de elos, nas fronteiras do estável e do instável. Os processos de 'organizar' os sujeitos e objetos (no sentido da sociomaterialidade) envolvidos em práticas de gerir se constituem como potencial objeto de estudo da gestão social, enquanto prática. Nesse caminho, é preciso superar também a visão reificada de organização para estabelecer que: “Compreender uma organização em particular envolveria, portanto, a compreensão do desenrolar das práticas de organizar através das quais uma dada organização estabelece certa estabilidade e se mostra como tal" (Santos \& Silveira, 2015, p. 93).

No âmbito da gestão social, a busca por pesquisas focadas no 'organizar' e no compreender as organizações, como fenômenos sociais, possui um grande potencial, quando se estuda, especialmente, movimentos sociais, economia solidária, protestos e manifestações, formações comunicativas na esfera pública e outras formas de organizar práticas (materiais, sociais e discursivas). Contribui de forma relevante, por exemplo, discutir e explorar os diversos loci da gestão social, por meio das práticas. Alcântara (2015) sistematizou como locus da gestão social presentes no campo: sociedade civil, terceiro setor, Estado, mercado, esferas públicas, espaços públicos, espaço intermediário, conselhos gestores, experiências participativas, movimentos sociais, parcerias trissetoriais, territórios, interorganizações e espaços públicos locais. Sendo, portanto, espaços plurais, heterogêneos e até que se contrapõem (Alcântara, 2015).

No entanto, a partir de Santos e Silveira (2015) é possível considerar que estes loci ainda se mantêm bastante superdimensionados e reificados, carecendo de um debate sobre as práticas e sobre a realidade vivida pelas pessoas nesses espaços (considerando elementos como corpo, coisas, conhecimento, linguagem, processos e indivíduos). Isto é, compreender as práticas de gestão social a partir dos arranjos de práticas, práxis e praticantes envolvidos, suas interações (cooperativas e conflitivas) em distintos horizontes de ação e momentos da vida cotidiana. Portanto, as contribuições das práticas se dirigem, nesse ponto, para a materialização de práticas de gestão social, no 'chão' das interações cotidianas, entre diversos atores/agentes/sujeitos em suas comunicações ordinárias, gestos, 
práxis e na relação com diferentes praticantes situados, em um contexto social e histórico - sendo necessário, portanto, estudar as práticas, os praticantes e as práxis, que são mobilizadas em cada um dos loci mapeados por Alcântara (2015) e acima citados.

(2) As relações constitutivas entre práticas, práxis e praticantes são categorias importantes para a compreensão das 'práticas de gestão social' e da 'gestão social como prática'.

Apesar dos conceitos de práticas serem diversos entre os diferentes autores, que constituem a virada para a prática, bem como entre aqueles que representam a segunda geração das teorias da prática (Postill, 2010), pesquisadores do campo de estudos da estratégia como prática oferecem a possibilidade de se estudar tais relações, por meio de um framework de análise composto por três categorias: práticas, práxis e praticantes (Whittington, 2006; Jarzabkowski, Balogun \& Seidl, 2007). Na interação entre elas, Jarzabkowski, Balogun e Seidl (2007) apresentam a constituição do strategizing, o trabalho estratégico. As relações entre estas categorias podem ser representadas, conforme Figura 1:

\section{Figura 1 - Estrutura de análise da relação entre práticas, práxis e praticantes}

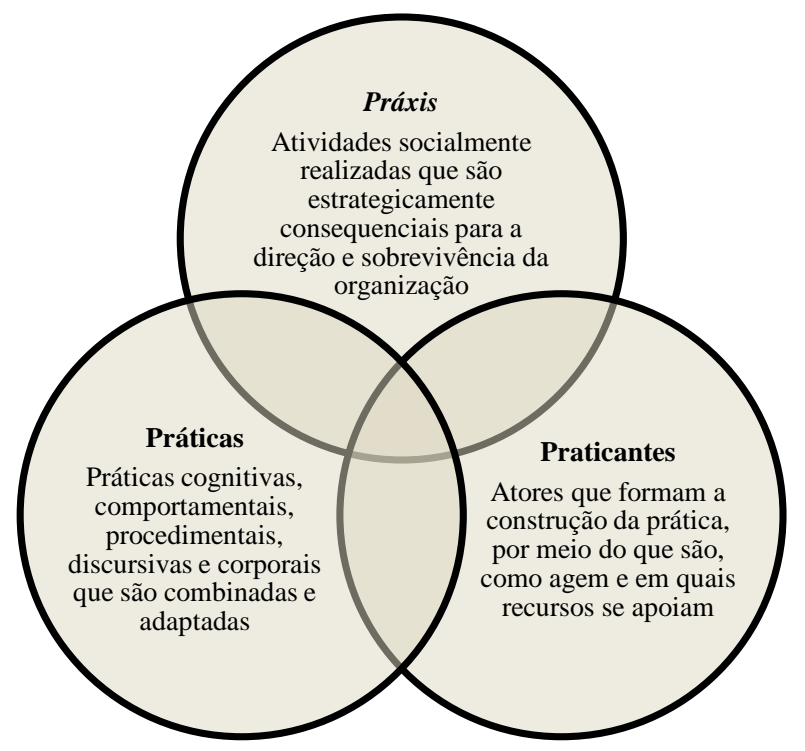

Fonte: Adaptado de Jarzabkowski, Balogun e Seidl (2007).

Este framework pode ser adotado para compreender as diversas relações entre práticas, práxis e praticantes na gestão social. Para tanto, as práticas podem ser analisadas no planejamento, nas reuniões e nos encontros, nas regras, nas normas, entre outros, seja em momentos de organizações formais e burocráticas, bem como em práticas de organizar com diferentes níveis de informalidade e de instabilidade. As análises também devem compreender os praticantes nos seus estoques de conhecimentos, nas experiências, nas motivações, nas razões, nas emoções, nos gestos corporais, nos conflitos interpessoais, entre outros elementos. Por fim, as práxis são observadas em apresentações, em textos institucionais e em conversas no cotidiano (Jarzabkowski, Balogun \& Seidl, 2007). Por isso, este artigo indica contribuições à gestão social, por meio destes elementos envolvidos nas práticas de gestão e no organizar. Sobre os atores, que participam das ações, os praticantes da gestão social, é importante considerar que:

No que se refere aos praticantes, faz-se necessário e essencial caracterizá-los, pois a prática só pode ser interpretada e entendida ao se enfocar grupos sociais e sujeitos específicos em seu fazer, investigando o que, como e porque eles fazem o que fazem, compreendendo como sustentam a prática, elementos de criatividade que fazem uso no dia a dia, rupturas e confrontos, assim como maneiras de significar e negociar a prática. (Venâncio, 2015, p. 6).

Essa atenção aos praticantes direciona para responder uma questão crítica, colocada por Pinho e Santos (2015b, p. 16), a saber: "Quem são os supostos sujeitos, hegemônicos ou contrahegemônicos da GS [gestão social]?". Isso é possível na perspectiva do estudo das práticas já que não se desconsideram as relações de poder, que se constituem. Um caminho é estudar como as práticas organizam relações hegemônicas e como se articulam, pois, na perspectiva de Chouliaraki e Fairclough (1999), as práticas se relacionam por meio de conflitos e tensões, em que as redes de práticas são mantidas por relações de poder e na medida em que a configuração do poder se move, as permanências das práticas mudam.

Assim, quando Tenório (1998) define gestão social como: "[...] um gerenciamento mais participativo, dialógico, no qual o processo decisório é exercido por meio de diferentes sujeitos sociais" - evidencia-se, nesta definição, a necessidade de compreender como os diferentes praticantes interagem entre si ao realizarem suas práxis, engajadas em práticas - e como lembra brevemente Peres Júnior (2013), na perspectiva de Giddens, é preciso compreender como as relações de poder se 
articulam nessas práticas: "A discussão sobre as relações de poder em contextos de práticas de gestão social, em particular a partir da perspectiva de mobilização de recursos pelos agentes" é uma agenda de pesquisa importante (Peres Júnior, Pereira \& Oliveira, 2013, p. 45).

Na visão das práticas e dos praticantes, existe também uma possibilidade de 'conversação' com a noção de públicos constituintes, conforme apresentado por Cabral (2011) e Cabral e Muzy (2014) no âmbito de projetos sociais - tendo em vista as relações: práticas sociais, fatos e valores. Além disso, emergem as possibilidades de pesquisas acerca da questão de quando e como os praticantes atuam em prol do desenvolvimento social, na perspectiva da gestão social de Fischer, Roesch e Melo (2006).

O enfoque em práticas, práxis e praticantes pode favorecer o entendimento dos pontos comuns e divergentes na pluralidade de temas da gestão social - ou "processos de gestão social heterogêneos" (Guerra \& Teodósio, 2015, p. 50). Focando nas práticas se pode conceber, na pluralidade, um ponto central da gestão social, identificando quais praticantes estão envolvidos, quais as práticas que realizam e as práxis que representam lembrando que as práticas são heterogêneas, assim como os processos de organizar. Finalmente, é importante compreender (por meio de pesquisa empírica) se nos diferentes espaços, esferas ou organizações, as relações entre práticas, práxis e praticantes são construídas para o fortalecimento de práticas democráticas e dialógicas de gestão, no sentido de Tenório (1998) - e, caso ocorra, em que medida isso se constitui.

\section{(3) A gestão social como vem sendo desenvolvida demanda} uma práxis, entendida como 'atividade social reflexiva e transformadora'.

Para avançar neste item é necessário ponderar o conceito de práxis, para além da concepção apresentada por Whittington (2006, p. 619), que o autor busca em Reckwitz (2002): “[...] a palavra grega 'praxis' refere-se à atividade real, o que as pessoas fazem na prática". Na gestão social, diversos autores (especialmente, na Abordagem Crítica Frankfurtiana, como denominam Peres Junior e Pereira, 2014) demandam uma ideia de práxis que é comum na perspectiva da Teoria Crítica.

Nos textos da estratégia como prática, essa concepção pode ser encontrada em Brito et al. (2014) que, apoiados em Vazquez (2007), qualificam práxis como ação refletida, de forma que: "[...] contrário da visão existente que toma a estratégia como algo informado pela ideologia gerencial, a noção de estratégia como práxis procura considerar a prática de modo reflexivo" (Brito et al., 2014, p. 6). Portanto, "a práxis é dialeticamente informada por reflexões teóricas que visam à transformação e a mudança de práticas" (Brito et al., 2014, p. 6). Esta definição se conecta com os textos de Tenório $(1998 ; 2005)$ e com a concepção apresentada por Shrivastava (1986), ao tratar da gestão como práxis:

Em oposição à mera ação, ou mera teoria, práxis é dialeticamente informada por considerações teóricas e visa alcançar mudanças práticas libertadoras. Sendo um conceito de ação, tem especial relevância para a prática gerencial. Mas ao contrário da orientação existente do campo onde a prática é informada por ideologias de gestão, a estratégia como práxis visa informar a prática com considerações teóricas. Teoria, especialmente na forma de crítica e da negação teórica, teoria que expõe e analisa as contradições organizacional e social com o objetivo de superálas, é um elemento importante da práxis [...]. (Shrivastava, 1986, p. 372).

Ainda sobre isso, Shrivastava (1986) entende também que o foco das pesquisas deve ser estudar as organizações como verbo (processos contínuos, que envolvem a vida material, social e cultural), em consonância com o já discutido aqui.

Adiante, a própria perspectiva das práticas concebe a agência dos indivíduos e também considera um elemento comum no âmbito das discussões de gestão social, a saber, a linguagem (Tenório, 1998; 2005; Alcântara, 2015; Cançado, Pereira \& Tenório, 2015). Segundo Chouliaraki e Fairclough (1999), as práticas possuem uma dimensão reflexiva, em que as pessoas geram representações do que elas fazem como parte do que elas fazem - portanto, nessa perspectiva, a visão de práticas não elimina a agência dos sujeitos, em que o discurso e a materialidade estão presentes nas práticas. Assim, a linguagem é importante, mas não mais que outros elementos das práticas, conforme coloca Reckwitz (2002). Para Schatzki (2001) o campo das práticas é o lugar para investigar e pesquisar fenômenos como: agência, conhecimento, linguagem, ética e outros.

Metodologicamente, para compreender nas pesquisas, as modalidades da práxis, Brito et al. (2014), com base em Vazquez (2007), sugerem as noções de práxis criadora, reiterativa ou imitativa, reflexiva e espontânea. A práxis criadora parte do pressuposto de que a relação próxima entre dimensões objetivas e subjetivas demonstra o caráter emergente e as possibilidades de alteração, ao longo do curso de ação, de modo reflexivo. A práxis reiterativa ou imitativa se vincula à reprodução acrítica das práticas, gerada em prescrições e modelos previamente estipulados. Segundo Brito et al. (2014, p. 7): "A práxis espontânea não possui caráter transformador, dada a naturalização e atomização das práticas". Por último, a práxis reflexiva afeta as próprias práticas, "apresentando as possibilidades de transformação da realidade e dos próprios praticantes" (Brito et al., 2014, p. 7).

Portanto, esses níveis podem ser utilizados para o estudo da práxis, no âmbito da gestão social, tanto nas práticas organizativas a esta vinculadas ou aos espaços, em que práticas de gestão social podem ocorrer (indica-se, a priori, que a gestão social, como tem se desenvolvido, demanda a ideia de uma práxis criadora, reflexiva e transformadora). Estas noções podem facilitar a compreensão das dificuldades (e possibilidades) enfrentadas pelos praticantes, no sentido das limitações nos ambientes institucionais dos quais fazem parte, e que podem ter circunscritas normas ou constrangimentos de vários tipos e ordens.

\section{Considerações Finais}

As teorias da prática buscam considerar e entender, de novas formas, uma diversidade de elementos da teoria social (Reckwitz, 2002). Há, portanto, mudanças significativas, que não são 
apenas de denominações dos fenômenos sociais. Assim, mostrase que a partir de autores como Schatzki $(2001 ; 2005)$, Reckwitz (2002) e Nicolini (2013), as práticas são entendidas como elementos fundamentais para a constituição e estudo da realidade social. A partir das relações entre práticas, práxis e praticantes da SAP argumenta-se que a gestão social, como vem sendo desenvolvida, demanda a práxis, entendida como atividade social reflexiva e transformadora que permite avançar no estudo e fomento de uma gestão social contextualizada. Essa visão possibilita um foco no estudo das práticas organizativas, superando também uma visão reificada do objeto organização (Peci, 2014). Nisso, este estudo segue a perspectiva de que as práticas são constitutivas da realidade social e organizacional (Feldman \& Orlikowski, 2011).

O foco nas práticas busca entender a gestão social, de forma processual, considerando os elementos heterogêneos de estabilidade e de mudanças da vida cotidiana, a sociomaterialidade e os atores envolvidos. Com isso, a proposta "aproxima a pesquisa do cotidiano, tornando mais rica a compreensão da realidade social, principalmente, por permitir uma leitura que se esforça em acompanhar a fluidez e incertezas dos fenômenos sociais" (Santos \& Helal, 2016, p. 10). Neste caminho, consideram-se alguns avanços proporcionados pelas teorias das práticas, especialmente, pela sua recepção a partir da estratégia como prática: (1) As abordagens da prática permitem avançar na discussão sobre o 'objeto de análise' da gestão social, enquanto campo plural/heterogêneo e abrem possibilidade de considerar como objeto (em sentido epistemológico), não apenas a 'organização' (reificada), mas o 'organizar práticas'; (2) As relações constitutivas entre práticas, práxis e praticantes são categorias importantes para a compreensão das 'práticas de gestão social' e da 'gestão social como prática'; e (3) A gestão social como vem sendo desenvolvida demanda uma práxis entendida como 'atividade social reflexiva e transformadora'.

Como limitação deste ensaio é possível destacar, principalmente, que as aproximações foram realizadas de forma inicial, não aprofundando nas diversas abordagens da gestão social e suas especificidades, nem da estratégia como prática e das teorias da prática. Cabe considerar, no entanto, que as indicações podem ser pensadas (operacionalizadas empiricamente) e problematizadas no campo da gestão social. Não se trata de exportar formas de conhecimento, mas buscar novos direcionamentos epistêmicos, tendo em vista as incompletudes cognitivas (Cf. Paes de Paula, 2015). Portanto, abrem-se portas no sentido apresentado por Paes de Paula (2015) para reconstruções epistêmicas e articulações entre interesses cognitivos - processos esses que devem ser dialéticos no sentido das possíveis tensões e contradições entre abordagens, teorias e métodos.

Por fim, apresenta-se um programa de pesquisas futuras que se pretende trilhar - as indicações representam uma agenda de pesquisa que se espera contribuir para sua construção, a partir do foco nas práticas.

a) Desenvolver uma abordagem epistemo-metodológica para a compreensão dos processos de legitimação de práticas de gestão social a partir das contribuições da Sociologia Pragmática de Boltanski e Thévenot;

b) Desenvolver pesquisas voltadas para a proposta de Clegg, Carter e Kornberger (2004), a partir das categorias: poder, identidade, atores não humanos, linguagem e instituições;

c) Ampliar os debates da gestão social na direção de outros autores e abordagens oriundas da virada para a prática;

d) Buscar as contribuições da perspectiva da gestão como prática (management as a social practice) proposta por Michael Reed;

e) Explorar como a ideia de ressignificação para o imaginário gerencial de Paes de Paula (2016) contribui para o desenvolvimento da gestão social, como forma dialógica de gestão;

f) Colocar em prática a agenda de pesquisa sobre as relações em práticas sociais e poder, no âmbito da gestão social, como sinalizado por Peres Júnior, Pereira e Oliveira (2013);

g) Estudar como diferentes práticas se articulam e ganham legitimidade, especificamente, como práticas de gestão social são construídas; e,

h) Estudos voltados para a noção de sociomaterialidade, uma questão atual e não contemplada pelos estudos do campo da gestão social.

\section{Referências bibliográficas}

Albino, J. C. A., \& Gonçalves, C. A. (2008, setembro). Estratégia como Prática: Uma proposta de Síntese? In: Anais do Encontro da Anpad, Rio de Janeiro, RJ, 32.

Alcântara, V. C. (2015). Mundo-da-vida e sistema: o locus da gestão social sob a abordagem habermasiana. (Dissertação de mestrado). Universidade Federal Lavras, Lavras, Brasil.

Araújo, E. T. (2012). (In) consistências da gestão social e seus processos de formação: um campo em construção. (Tese de doutorado). Pontifícia Universidade Católica de São Paulo, SP, Brasil.

Araújo, E. T. (2014). Gestão Social. In: Boullosa, R. F. (Org.). Dicionário para a formação em gestão social. Salvador: CIAGS.

Bourdieu, P. (1990) The logic of practice. Oxford: Polity.

Brito, M. J., Brito, V. G. P., Borges, A. F., \& Andrade, L. P. (2014, setembro). Proposta teórico-metodológica para o estudo da Estratégia como Prática Social: uma abordagem construcionista. Anais do Encontro da Associação Nacional de Pós-Graduação e Pesquisa em Administração, Rio de Janeiro, RJ, Brasil, 38.

Cabral, E. H. S. (2011). Valores e espaço público: referenciais e instrumentos para a avaliação de projetos sociais. Revista de Administração Pública, 45(2), 1915-1941.

Cabral, E. H. S., \& Muzy, P. T. (2014). Os valores e o valor da moeda: hipóteses sobre a comensurabilidade e a monetarização do impacto de projetos sociais. Cadernos EBAPE.BR, 12(2), 339-356.

Cançado, A. C. (2011). Fundamentos teóricos da gestão social. (Tese de doutorado). Universidade Federal de Lavras, Lavras, MG, Brasil.

Cançado, A. C., Pereira, J. R., \& Tenório, F. G. (2015). Gestão Social: epistemologia de um paradigma (2 $2^{\mathrm{a}}$ ed.). Curitiba: Editora CRV.

Cançado, A. C., Tenório F. G., \& Pereira, J. R. (2011). Gestão social: reflexões teóricas e conceituais. Cadernos EBAPE.BR, 9(3), 681-703.

Chouliaraki, L., \& Fairclough, N. (1999). Discourse in late modernity: Rethinking critical discourse analysis. Edinburgh University Press.

Clegg, S. R., Kornberger, M., \& Rhodes, C. (2005). Learning/Becoming/Organizing. Organization, 12(2), 147-167.

Clegg, S., Carter, C., \& Kornberger, M. (2004). Get up, I feel like being a strategy machine. European Management Review, 1(1), 21-28.

Corradi, G., Gherardi, S., \& Verzelloni, L. (2010). Through the practice lens: Where is the bandwagon of practice-based studies heading?. Management learning, 41(3), 265-283.

Fein, E. (2015). Reviewing the Practice Turn in Social, Organizational and Leadership Studies from an Integral Perspective. Integral Review, 11(3), 93-116.

Feldman, M. S., \& Orlikowski, W. J. (2011). Practicing Theory and Theorizing Practice. Forthcoming. Martha S. Feldman and Wanda J. Orlikowski. Organization Science, Special Issue Perspectives on Organization Science: The First 20 Years. 
Fischer, T. (2012). Gestão social do desenvolvimento de territórios. Revista Psicologia, 12(1), 113-119.

Fischer, T., Roesch, S., \& Melo, V. P. (2006). Gestão do desenvolvimento territorial e residência social: casos para o ensino. Salvador: UFBA, 2006.

Foucault, M. (1979). Microfísica do poder. Rio de Janeiro: Graal

França Filho, G. C. (2003, junho). Gestão Social: um conceito em construção. Anais do Colóquio Internacional Sobre Poder Local, Salvador, BA, Brasil, 9.

França Filho, G. C. (2008). Definindo gestão social. In: Silva Junior, J. T., Mâsih, R. T., Cançado, A. C., \& Schommer, P. C. (Org.). Gestão social: práticas em debate, teorias em construção. Fortaleza: Imprensa Universitária, 26-37.

Garcia, A. S. (2016). Esferas públicas como categoria fundante da gestão social. (Dissertação de mestrado). Universidade Federal de Lavras, Lavras, MG, Brasil.

Gherardi, S. (2006). Organizational knowledge: the texture of workplace learning. Oxford, UK: Blackwell Publishing.

Giddens, A. (2003). A constituição da sociedade. São Paulo: Martins Fontes.

Golsorkhi, D., Rouleau, L., Seidl, D., \& Vaara, E. (2010). Cambridge Handbook of Strategy as Practice. Cambridge: University Press.

Gondim, S., Fischer, T. M. D., \& Melo, V. P. (2006, setembro). Formação em Gestão Social: um olhar crítico sobre a experiência de pós-graduação. Anais do Encontro da Associação Nacional de Pós-Graduação e Pesquisa em Administração, Salvador, BA, Brasil, 30.

Guerra, J., \& Teodósio, A. S. S. (2015). Dialogismo e reflexidade: uma análise da contribuição dos centros e programas de estudos de gestão social no brasil. Revista de Ciências da Administração, 1(3), 45-62.

lizuka, E. S., \& Junqueira, L. A. P. (2013). Produção acadêmica em gestão social: visita aos anais dos Enapegs de 2007 a 2012. Revista de Gestão Social e Ambiental, 7(2), 71-85.

Jarzabkowski, P., \& Spee, A. P. (2009). Strategy-as-practice: A review and future directions for the field. International Journal of Management Reviews, 11(1), 69-95.

Jarzabkowski, P., Balogun, J., \& Seidl, D. (2007). Strategizing: The challenges of a practice perspective. Human Relations, $60(1), 5-27$.

Justen, C. E., Moretto Neto, L., \& Garrido, P. (2014). O. Para além da dupla consciência: Gestão Social e as antessalas epistemológicas. Cadernos EBAPE.BR, 12(2), 237-251.

Nicolini, D. (2013). Practice theory, work, and organization: An Introduction. Oxford: Oxford University Press

Nicolini, D., \& Monteiro, P. (2017). The practice approach: for a praxeology of organisational and management studies. The SAGE Handbook of Process Organization Studies, London: SAGE.

Paes de Paula, A. P. (2015). Repensando os Estudos Organizacionais: por uma nova teoria do conhecimento. Rio de Janeiro: FGV.

Paes de Paula, A. P. (2016). Em busca de uma ressignificação para o imaginário gerencial: os desafios da criação e da dialogicidade. Revista de Administração Mackenzie, 17(2), 18-41.

Peci, A. (2014). Réplica 3 - Clássicos... Quais clássicos? Antinomias e tensões no fazer ciência em administração. Revista de Administração Contemporânea, 18(5), 726-735.

Peres Júnior, M. R. (2013). Gestão Social sob a ótica da Teoria da Estruturação. (Tese de doutorado). Universidade Federal de Lavras, Lavras, MG, Brasil.

Peres Júnior, M. R., \& Pereira, J. R. (2014). Abordagens Teóricas da Gestão Social: uma análise de citações exploratórias. Cadernos EBAPE. $B R, 12(4), 221-236$

Peres Júnior, M. R., Pereira, J. R., \& Oliveira, L. C. D. (2013). Gestão Social sob a lente estruturacionista. Revista de Administração Mackenzie, 14(6), 18-49.

Pinho, J. A. G. (2010). Gestão social: conceituando e discutindo os limites e possibilidades reais na sociedade brasileira. In: Rigo, A. S. et al. Gestão Social e Políticas Públicas de Desenvolvimento: Ações, Articulações e Agenda. Recife: UNIVASF.

Pinho, J. A. G., \& Santos, M. E. P. (2015a). Gestão social: uma análise crítica de experiências brasileiras. Revista do Serviço Público Brasília, $66(2), 257-279$
Pinho, J. A. G., \& Santos, M. E. P. (2015b). Aporias em torno do conceito de Gestão Social: dilemas teóricos e políticos. REGE - Revista de Gestão, 22(2), 155-172.

Postill, J. (2010). Introduction: Theorising media and practice. In Bräuchler, B., \& J. Postill (eds). Theorising Media and Practice. Oxford and New York: Berghahn.

Reckwitz, A. (2002). Toward a Theory of Social Practices: A development in culturalist theorizing. European Journal of Social Theory, 5(1), 243-263.

Santos, E. C. \& Helal, D. H. (2016) Relações de trabalho e práticas: aproximações teóricas. In: IX Encontro de Estudos Organizacionais da ANPAD (IX ENEO), Belo Horizonte. Anais do IX Encontro de Estudos Organizacionais da ANPAD, Belo Horizonte.

Santos, L. L. S., \& Silveira, R. A. (2015). Por uma Epistemologia das Práticas Organizacionais: A contribuição de Theodore Schatzki, Organizações \& Sociedade, 22(7), 79-98.

Schatzki, T. R. (2001). Practice mind-ed orders. In: Schatzki, T. R., KnorrCetina, K., \& Von Savigny, E. (eds.) The practice turn in contemporary theory. London: Routledge.

Schatzki, T. R. (2005). Peripheral vision: The sites of organizations. Organization studies, 26(3), 465-484.

Schatzki, T. R., Knorr-Cetina, K., \& Von Savigny, E. (2001). The practice turn in contemporary theory. London: Routledge.

Schommer, P. C., \& França Filho, G. C. de. (2006) A metodologia da residência social e a aprendizagem em comunidades de prática. Revista Eletrônica da Residência Social do CIAGS/UFBA,1(1), 203-226.

Shrivastava, P. (1986). Is Strategic Management Ideological? Journal of Management, 12(3), 363-377.

Silva, A. R. L., \& Pimentel, T. D. (2014, novembro). A estratégia como prática no processo de auto-organização e gestão social. Anais do Congresso Brasileiro de Estudos Organizacionais, Uberlândia, MG, Brasil,

Silva, E. R. D., \& Gonçalves, C. A. (2016). Practice genealogy and its implications for strategy as practice. Revista de Administração Mackenzie, 17(4), 130-152.

Soares, L. C., \& Bispo, M. S. (2017). A aprendizagem do cozinhar à luz das práticas sociais e da estética organizacional. Brazilian Business Review, 14(2), 247-271.

Tenório, F. G. (1998). Gestão social: uma perspectiva conceitual. Revista de Administração Pública, 32(5), 7-23.

Tenório, F. G. (2005). (Re)visitando o conceito de gestão social Desenvolvimento em Questão, 3(2), 101-124.

Universidade Federal Do Rio Grande Do Sul. IX Encontro Nacional de Pesquisadores em Gestão social - Gestão Social, Participação e Desenvolvimento: Olhares desde a América Latina. Disponível em: <https://www.ufrgs.br/enapegs2016/>. Acesso em: 20 nov. 2015.

Vaara, E., \& Whittington, R. (2012). Strategy-as-Practice: Taking Social Practices Seriously. The Academy of Management Annals,6(1), 285-336.

Vandenberghe, F. (2014, abril). Gestão social: Uma disciplina em busca de teoria. Anais do Encontro Nacional de Pesquisadores em Gestão Social, Cachoeira, BA, Brasil, 8.

Vazquez, A. S. (2007). Filosofia da Práxis (2ª ed.). Rio de Janeiro: Editora Paz e Terra.

Venâncio, A. C. L. (2015, outubro). Metodologias das práticas. Anais do Congresso Brasileiro de Estudos Organizacionais, Vitória, ES, 3.

Verzelloni, L. (2016). Beyond the Provisional Nature: Towards a Radial Concept of Practice. Teoria e Prática em Administração, 6(2), 01-25.

Walter, S. A., \& Augusto, P. O. M. (2012). Prática estratégica e strategizing: mapeamento dos delineamentos metodológicos empregados em estratégia como prática. Revista Eletrônica de Ciência Administrativa, 11(1), 131-142.

Warde, A. (2005). Consumption and theories of practice. Journal of consumer culture, 5(2), 131-153.

Whittington, R. (1996). Strategy as practice. Long Range Planning, 29(5), 731-735.

Whittington, R. (2006). Completing the practice turn in strategy research. Organization Studies, 27(5), 613-634.

Zwick, E., Silva, I. C., \& Brito, M. J. (2014). Estratégia como prática social e teoria da ação comunicativa: possíveis aproximações teóricas. Cadernos EBAPE.BR,12(4), 384-400. 